\title{
Towards an Understanding of Mature Writing: Analyzing and Paraphrasing Complex Noun Phrases'
}

\author{
Michael Jordan, \\ Queen's University
}

This article challenges the commonly held view that long sentences and complex structures are undesirable features of writing. Indeed the claim is made that, for prose intended for mature readers, iviters must learn to use complex noun phrases in long sentences to emulate effective mature writing. Based on a scholarly article by an award-winning writer, the analysis explains how -ed, -ing, relative, verbless, prepositional, and to-infintitive clauses are used to create complex postmodified noun phrases in different positions in the sentence. For each example, a paraphrase is offered which does not use a complex noun phrase, and the two versions are compared. In addition, anaphoric complex noun phrases are briefly discussed.

\section{Background and Motivation}

\section{Readability Formulas}

TRADITIONAL WISDOM IN TECHNICAL WRITING informs us that we should create relatively short sentences to make our writing more readable. Flesch (1951), Gunning (1968) and others have provided us with formulas for calculating the readability of texts based largely on sentence length and

1. I am most grateful to Michael Bell, the author of the article used as the basis for this work, for his permission to use his writing in this way; and to Queen's Quanterly, the publishers, for also giving me their permission. I am also indebted toThe Strathy Language Unit in the Department of English at Queen's University for allowing me to use their facilitics for this analysis. 
syllable counts. Other formulas (e.g., by Dale and Chall, [1948]) rely more on vocabulary. There is a rich literature of discussion on the relevance and use of such methods as a guide to readability; see Karlinsky and Koch (1983) and Giles (1990) for details of some of the arguments presented and bibliographies on the subject. More recently, style guides have been programmed with the same notion, and they are quick to point out long sentences for the writer to re-examine. In addition, most textbooks give similar advice to their readers.

Readability formulas have their advocates, especially for evaluating texts appropriate for the general public or similar levels of writing al ility. Sclienck (1977), with some reservations, recommends their use for improving word and sentence length, and Powel (1981) advocates their use as a writing guide but feels they lack real help in editing. In contrast, McClure (1987) advises us to use readability formulas only after a draft is complete. And Vervalin (1980) suggests that writers use the simple Gunning Fog Index to write shorter sentences and vary sentence length.

It is thus with some trepidation that I here venture to suggest that we take a wider view of readability-at least for prose for mature readers-by acknowledging that some genres of writing demand long sentences and complex structures as an essential element of the genre. (I am assuming, of course, that this genre-discursive language analysis for specialists in the subject-is one such genre.) My approach here follows the reasoning of Plung (1981), who points out that readability formulas do not "make allowances for the ... differences among various reading audiences" (p. 52). Plung also suggests that we advise technical writers to improve their writing "not with the use of readability formulas designed with application to other forms of writing, but with the insight of professionals who recognize the true complexities of technical writing" (p. 54).

Plung's view is supported by Bruce, Rubin and Starr (1981), who claim that readability formulas fait to accome for "backpround knowledge of the reader ... the purpose of the reader... and the purpose of the person who is presenting the text to the reader"(p. 54). Redish (1981) identities many inportant variables not included in readability formulas, and Drury (1985) points out that the formulas fail to account for sentence structure.

The general argument made recently by Wilkinson (1992) explaining the use of jargon and the passive voice also applies here. Claiming that we must understand and teach the fact that there are many genres and rhetorical situations, Wilkinson explains that we and our students must adapt our writ- 
ing styles according to the need and audience of the document. This view is in line with stylistic analyses (e.g., by Crystal and Davy [1959]) of the many genres of language and work in genre theory and register analysis. Although the importance of audience appreciation has been a cornerstone of our specialty since its inception, this vital understanding of audience, purpose and mode of the document still seems illusive to many.

\section{Pedagogical Applications}

Even more controversially, perhaps, I am claiming that many engineering students have a greater difficulty in creating flowing prose with complex noun phrases and structures than they have in writing "plainer" prose-prose that would meet the requirements of readability formulas and the advice based on them and their premises. Because we have become pedagogically attuned to encouraging students to use short sentences and simple clause and sentence structures, our discipline has tended to concentrate on the related inter-sentential and inter-clausal connections.

Thus many textbooks explain how to use-and not use- "which," "this,"acronyms, synonyms, the grammar of ellipsis and parallel structure, punctuation with non-restrictive clauses and lists, and other features of a relatively simple prose style. In contrast, beyond relatively simple sentence combining (Strong, 1973), we have failed to address the need to help students to develop an ability to combine their thoughts in the way that experienced writers do: using long and complex restrictive clauses and subordinations in long and complex sentences.

The deficiency has been both in teaching and research, and it is difficult to assess which should bear the greater blame. Teachers can claim that they have not been told that writing for mature readers is extremely complex, and that in any event their major task is to make sure that students can write at least quite simple prose. We obviously need more detailed research into complex prose style to sec this record straight. Yet surely teachers must realize that the readability fomulas and the simplistic rules of "effective" writing are far from adequate for mature prose, and that their writing itself (apart from the sociology of audience appreciation, the psychology of the writing process, formats, and rules of usage) is inadequate.

Most researchers of non-literary writing have studiously avoided the difficult task of analyzing how good writers write, choosing instead to study the profession, audience, purpose, process, format, and usage instead of the 
actual language structures that we should be teaching our students to emulate. Thus, for teachers who are aware of the need to teach complex writing, there is little they can use as the basis for meaningful instruction. This article secks to provide some of the essentials for the creation of a theoretical franework to explain the complexities.

\section{Motivations}

As an attempt to stimulate research and teaching of mature writing, I have chosen to concentrate here on what is perhaps the central feature of mature writing: the complex structures involved in postmodified restrictive clauses. Specifically, I am seeking to find ways of accounting for their complexities, and of helping students to convert less complex writing into the style used by very skilled writers of English. I have become aware of this subject as an important area of research and teaching from three independent sources.

The first of these sources resulted from my recent efforts to do the very opposite: to convert complex structures including restrictive postmodified noun phrases into "plain" language suitable for readers with limited linguistic comprehension abilities (Jordan, 1994). This work has been developed to explain many of the complexities in terms of established inter-clausal semantic relations. Further work applying the principles to improving the readability of parts of a Canadian Act has been developed, and the project is currently being developed further to explain conditions in legal writing and theoretical principles of complex cohesion in English.

Clearly, the challenge was to see whether the principles could be applied in reverse, given that, in paraplarasing in either direction, there are bound to be changes in style, emphasis and colnesion. Thus the aim here is to apply the principles of paraphrasing clauses into complex noun phrases as the basis for teaching students to produce writing for very mature readers. At the same time this paper documents the types and uses of restrictive postmodifiers in English.

The second source of motivation for this work occurred during my recent work on the corpus of The Strathy Language Unit at Queen's University, Kingston, Ontario, Canada. This corpus contains a large variety of texts of recent Canadian English use, together with the means of accessing words and groups within the texts. One of these texts is an article entitled "Museums and Federal Cultural Policy" by Michael Bell, which appeared in 
Queen's Quarterly, Autumn, 1987. Beautifully written and distinguished as a Governor-General's $A$ ward winner for non-fiction, this article nonetheless (or perhays therefore) consists predominantly of long sentences and long, complex noun phrases. The article would no doubt be rejected out of hand by any self-respecting style checker, yet for intended readers it is a model of clarity, smonth transition and macure style. Mr. Bell's article provided an important stimulus fior my study of complex noun phrases in mature writing, and it is used as the basis for this present analysis.

\section{The Pedagogical Motivation}

The third motivation for this present work derives from my attempts over the years to encourage students to convert their often quite simple prose into a style morc appropriate for professional readers. After some instruction and practice, most of my senior engineering students can write sound descriptions and explanations using relatively simple clauses and sentence structures. Yet I have found great difficulty in helping them to combine their ideas using the more complex structures employed by skilled writers. The students' writing can be criticized because of their short sentences, overuse of existential "there", poor connections with "this" and "it" (few know the difference), use of only relative clauses instead of all the types of restrictive and non-restrictive clauses, and overuse of coordination. Even when specifically asked to combine ideas using a style appropriate for mature readers, few are able to use subordination. Even fewer seem able to use associations or restrictive postmodifiers in their writing. Here is a typical example of student writing:

John Hopkins University is in Laurel, Maryland and researchers there have devised a new technique. This technique will produce nitrogenbased materials, and could form the basis of a new class of semiconductor laser. Some semiconductors are currently in use. These are compounds of arsenic; examples are gallium arsenide, aluminum arsenide, and indium arsenide.

While this style cannot be criticized for its grammar or clarity-and it would certainly pass readability tests and be approved by style checkers-it is stylistically unacceptable. Skilled writers for mature readers simply do not write like that! The short sentences, the two co-ordinations, and the overuse of "this" and "these" are obvious signs of a style more appropriate for readers at 
perhaps a Grade 11 or 12 level. Less obvious signs are the simple subjects, the paucity of complex noun phrases, and the lack of subordination. Now compare this style with that of the original document:

(1) Researchers at John Hopkins University in Laurel, Maryland, have devised a technique to produce nitrogen-based materials that could form the basis of a new class of semiconductor lasers .... The semiconductor lasers currently used are compounds of arsenic, such as gallium arsenide, aluminum arsenide and indium arsenide. (New Scientist, 21 April 1988, p. 31)

This original text has longish sentences and has long subjects containing complex postmodifications; it also includes subordination and a long object and complement. No doubt a style checker would be horrified at being faced with two complex sentences containing nearly fifty words, yet the style is appropriate for the readers. Our understanding of "effective" writing must accommodate the teaching of such real prose to mature readers in our curricula.

\section{Sentence Combining}

I am advocating here that we can and should expect students to develop the ability to convert their often rather simplistic styles of writing to suit mature writers for at least some of their work. This means that they need to be able to combine short, simply-structured clauses and sentences into much more complex forms-those used by skilled and experienced writers. Some of the principles of sentence combining have been known for some time, and some texts provide drills to help students to combine ideas using nonrestrictive clauses and adjectives. An example is:

1. The cars cane cruising up Broadwaly.

2. The cars are glittering.

3. The paint is harsh.

4. The paint is metallic.

5. The paint is highly waxed.

6. There is a rumble of exhaust.

7. The rumble is great.

8. Lights explode softly off the scene.

9. The lights are for the street.

10. The scene is primitive. (Strong, 1973, p. x) 
Students are asked to combine these ideas using a more mature style, and two "transformations" are offered:

1. The glittering cars come cruising up Broadway. Their paint is harsh, metallic and highly waxed. There is a great rumbling of exhaust. Street lights explode softly off the primitive scene.

2. The cars that glitter come cruising up Broadway. Their metallic paint is harsh and highly waxed. There is a great rumble of exhaust. Lights on the street explode softly off the scene--which is primitive. (Strong, 1973, p. xi)

While there are obvious problems with this example, the aim is laudable, though at an extremely low level of composition. More worrisome, though, is that the students are left entirely to their own devices, it being claimed that "every person who uses a language in his day-to-day life is a language expert" (Strong, 1973, p. xiii). Although this is true at lower levels of composition, we cannot assume that all our students have developed a knowledge or understanding of the complex features of mature writing style. And it is certainly not the case that technical writing teachers are consciously aware of elements of mature style.

There is also work available that extends this simplistic sentence-combining approach into using -ed, -ing, and verbless clauses as well as relative clauses for editing texts (Jordan, 1986a). In addition, a worked example of editing contains restrictive clauses as well (Jordan, 1986b), although it does not provide any related analysis or explanation. We now need to build on this earlier work. For writing for mature writers, restrictive clauses and complex noun phrases play important cohesive and stylistic roles, and we therefore need to understand what they mean and how they contribute to the style and collesion of the ext. We also need to know how to convert simpler linguistic structures intorest in tively possumodified clanses.

\section{Linguistic Background and Importance of the Subject}

The grammar and types of restrictive and non-restrictive postmodified noun phrases have long been of interest (Sweet, 1981), and many grammarians have discussed the subject (e.g., Jespersen, 1940; Poutsma, 1926-29). The various types of clauses (relativè, - -ed, -ing, verbless, prepositional, toinfinitive) have been well analyzed in isolated examples (Scheurwegs, 1959), 
although their complex combinations have been inadequately studied. Some detailed accounts of the meanings and uses of the varinus types of restrictive and non-restrictive clauses are also available (Quirk et al, 1985).

Of specific importance for this present study is the work of Johamnesson (1983), who studied thousands of examples of English use ranging fiom unreliearsed speech o very formal puse. Ile considesed all types of postmodification, and recognized the various levels of complexity and their relation to genre. He discovered a strong correlation between the use and complexity of postmodifying restrictive clauses and the formality of the language: the greater the formality, the greater the use of postmodifications to create complex noun phrases. Clearly complex noun phrases are distinctive markers of formal writing. The obvious pedagogical corollary is that writers must learn to use complex noun phrases if they are to emulate skilled writers.

Lest it be thought that $I$ exaggerate the claim that complex noun phrases are important elements of a mature writing style, I include below a fairly typical paragraph from Michael Bell's article used as the basis for this analysis. The large noun phrases and other features are italicized to facilitate recognition.

(2) As a result of its review of the National Museum and the other musetums in the federal structure the Massey Commission recommended the formation of a National Historic Musetum to be named the Canadian Historical Museum. Both the Museum of Natural History and the Canndian Historical Museum were to have their own boards of trustees and directors with access to the Minister through whom the Museums were to report to Rurliament. The National Gallery would serve as the model. In addition the Commission recommended the creation of a Canadian Museum of Science to be directed by the National Research Council. (p. 554)

Clearly, complex noun phrases play important roles in mature writing. It is vital for us to understand how they work in text if we wish to help students to emulate such prose.

\section{Converting Clauses Into Complex Noun Phrases}

The discussion in this section shows how writers can convert statements and ideas in clauses and sentences into complex restrictively-modified noun phrases. For each example, the information is first given in relatively 
primitive style, followed by the original form published in the article used for this analysis. Related discussion explains the principles involved.

This section is structured according to types of clauses. First -ed, ing and elative clauses are analyzed, followed by discussion of verbless and prepusitional clanses, and hen wo-infinitives, coordination and split nominals. The final subser inne discuss cohe sive elenents of complex noun phases, dealing with associated nominals and related methods.

I am taking for granted that readers have an understanding of restrictive (or defining) and non-restrictive (or non-defining) clauses. For the purpose of most of this article, I use the quite simple distinction that non-restrictive clauses are incidental information that can be-and usually are-separated from the remainder of the sentence by commas, or occasionally dashes or parentheses. There is, however, a cline of restrictiveness including levels of restrictiveness, but that distinction is not a vital part of the discussion here. The types of restrictive clauses are defined and explained as they are introduced.

\section{Using -ed Clauses}

Clauses dominated by the -ed form of the verb are called -ed clauses. Here is an example of a non-restrictive-ed clause:

(3) This policy, biased towards the individual artist and individual artistcurator and against established institutions, has been detrimental to the public art muscums (p.557).

The-el chase is all the text between the commas, and it is clearly seen to be non-restrictive because it does not restrict, define or limit the meaning of the preceding noun "policy". The commas reflect that textual meaning. The -ed form of the verb is so called because most of them end in -ed, although there are many irregular -ed forms in English. It is not called a "past" form simply because it often has nothing to do with the past; all -ed clauses are tenseless passives (no tense is indicated), and in this example any assumed time frame would be the present. Common uses for the -ed form, in addition to past active tenses, are the past, present and future passives. Here is an example

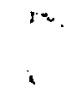


using a postmodified noun phrase:

Why has there been such a radical change in the perception of the National Art Gallery? The gallery is an institution which is entrusted with the stewardship of our national collections of art.

(4) Why has there been such a radical change in the perception of the National Arts Gallery, an institution entrusted with the stewardship of our national collections of art? (p. 552)

As tense is unimportant here ("has been" could well have been used instead of "is"), the -ed clause is ideal. The complex noun phrase, the whole of the text after the comma, is a verbless clause (more on those later) in partial apposition with the National Art Gallery. The -ed clause ("entrusted ... art") restricts the meaning of the preceding noun "institution", and therefore the complex noun phrase is restrictively postmodified by the -ed clause.

I need to point out that the term "clause" is used here and in the related literature in a wider sense than is often used in traditional approaches, in which a passage of text is only a clause if it contains a finite verb. The reason for this choice will be clear later, when we compare -ed and -ing clauses with relative clauses.

Example 4 shows how an -ed clause is used in a complex noun phrase at the end of a complex sentence. The following is an example in which the sentence starts with a complex noun phrase postmodified with an -ed clause:

A short-lived Conservative government was led by Prime Minister Joe Clark. It initiated during its tenure a review of federal cultural policy to be chaired by Louis-Applebaum, retired Executive Director of the Ontario Arts Council.

(5) The short-lived Conservative govermment led by Prime Minister Joe Clark initiated during its tenure a review of federal cultural policy to be chaired by Louis-Applebaum, retired Executive Director of the Ontario Arts Council. (p.557)

The -ed clause "led by Prime Minister Joe Clark" is an agentive tenseless 
passive defining the government being referred to. Note that the use of the indefinite article for the formal introduction is changed to the definite article in the original version because the noun phrase is now a defined topic. This example also includes a restrictive passive to-infinitive clause ("to be chaired by Louis-Applebaum") and a non-restrictive verbless clause in apposition at the end. (This last clause is not an -ed clause as "retired" here is an adjective, not a verb form.) An index at the end of this article lists and identifies all restrictive and non-restrictive clauses in the examples cited.

Restrictive -ed clauses occur in many textual environments with other forms of restrictive connection within complex noun phrases. An example with two coordinated -ed cla uses is:

This was an example of a classic management weakness of divided responsibility. This weakness is decried in every basic management text and avoided in every successful organization.

(6) This was an example of the classic management weakness of divided responsibilitydecried in every basic management text and avoided in every successful organization. (p.556)

As "This" re-enters two large preceding sentences, and we need to re-enter the preceding noun phrase as the subject of the second sentence, we cannot use "This" again, and so the rather cumbersome "This weakness" is used in the paraphrase. The whole difficulty is avoided by the original text, which uses two restrictive -ed clauses in coordination with "and."

\section{Using -ing Clauses}

Restrictive and non-restrictive clanses dominated by the -ing form of a verb are called-ing clauses. Some-ing clauses are used to indicate the means by which something is dune or to indicate a cause-effect relationship between clauses (Jordan, 1992); others provide information about a noun. In the first example the restrictive -ing clause provides further information:

The task force surveyed the country at a time when the art museums were very tender and distressed. It was bound to be exposed to strong presentations, and these would reflect recent experience. 
(7) The task force surveyed the country at a time when the art museums were very lender and distressed. It was bound to be exposed to strong presentations reflecting recent experience. (p. 563)

The awkwardness of the first version is partly due to the three short chases, but is alsu created by the need on indicar modality and/or tense with the verb "reflect." Should "would be" or "would be bound to be" be used instead, or should the modal be omitted to create an author assessment at this point in the text? The need to make such a decision is avoided by the restrictive -ing clause "reflecting recent experience."

The complex noun phrase in Example 7 is at the end of the sentence. Here is an example in which the -ing clause postmodifies the subject of the sentence:

Throughout most of 1986 trustees, members and workers participated in the examination of the ills of the National Museums of Canada. The participants represented some two thousand of Canada's museums, public art galleries and other heritage organizations.

(8) Throughout most of 1986 trustees, members and workers representing some two thousand of Canada's museums, public art galleries and other heritage organizations participated in the examination of the ills of the National Muscums of Canada. (p. 552)

In the original the second sentence becomes the restrictive -ing clause "representing ... organizations" to create a complex subject for the sentence.

While-ing clauses can be useful at the start and at the end of sentences, they prove even more useful when they create complex noun phrases in the middle of sentences. Here is such an example:

The judgments of its staff, often closer to art criticism than to the history of art, are very sensitive decisions. They contribute to the formation of our visual culture, and of all such decisions these judgments are among the most sensitive. They need to be safeguarded from direct political intervention. 
(9) The judgments of its staff, often closer to art criticism than to the history of art, are among the most sensitive decisions contributing to the formation of ou visual culture and need to be safeguarded from direct political intervention. (p. 562)

It is exturmely dillie wh to paraphase the original without using a restrictive postmodifier, and the difficulties with the first version are self evident. This example contains a non-restrictive verbless clause ("often ... history of art"), which adds to the complexity of the sentence.

\section{Using Relative Clauses}

Relative clauses are dominated by the relative pronouns "which," "that," "who," "where," and "when." Whereas "that" is used only for restrictive clauses, all the others are used for both restrictive and non-restrictive clauses. Thus, except when the writer elects to use "that" for a restrictive clause, we must rely on the sense of the text and the presence or absence of commas to recognize whether the clause is restrictive or not. The same applies for-ed and -ing clauses of course, so there is no additional difficulty in interpreting the meaning of relative clauses.

Both -ed and -ing clauses can usually be converted into relative clauses. For-ed clauses, we simply add a relative pronoun plus a form of the verb "to be." For -ing clauses, we have to add a relative clause and change the verb form. Because of the close affinity between -ed, -ing and relative clauses, it is convenient to call them all clauses, and define the term "clause" to include passages of text dominated by non-finite as well as finite verb forms.

In the article being studied, the writer uses "that" rather than "which" for his relative clauses. Here is an example where the relative clause occurs at the end of the sentence. To add to the value of this example, the paraphrase is offered for the included -ed clauses as well.

Most hoped that the National Museums Task Force, chaired by William Withrow and Clement Richard, would be able to arrive at a diagnosis and recommend a treatment. This would help the four national museums take a position of leadership. This position would be based on muscum performance, not national designation. 
(10) Most hoped that the National Museums Task Force, chaired by William Withrow and Clement Richard, would be able to arrive at a diagnosis and recommend a treatment that would help the four national museums take a position of leadership based on museum performance, not national designation. (p. 552)

The complex nominal in the original ("a treatment ... designation") contains a restrictive relative clause ("that ... designated") postmodifying the head noun "treatment." Within that relative clause there is a restrictive-ed clause ("based ... designated") postmodifying the complex head "position of leadership."

In the following example the relative clause occurs as part of the subject of the sentence. The sentence also contains a restrictive -ed clause:

A committee carried out the review under the Liberals. It produced the Report of the Federal Cultural Policy Review Committee. The report being referred to was published in 1982.

(11) The committee that carried out the review under the Liberals produced the Report of the Federal Cultural Policy Review Committee published in 1982. (p. 557)

The paraphrase is particularly awkward at the end as it was necessary to include the "restrictive" semantics involved, that is, the committee produced several reports and we are just referring to this particular one. The original avoids the need for any such contrivance, incorporating the restrictive relative clause as part of the subject of the sentence.

The complexity increases as the relative clanse becomes more embedded within structures of a complex sentence. lles is an example where the restrictive relative clanse is pant of a cutasi-comjonincel subject:

The National Gallery staff, along with interested parties outside the museums (often former directors) and others, lobbied actively for the dismantling of The Corporation. The others involved in this action were members of museums, and these museums make up a substantial portion of The Corporation. 
(12) The National Gallery staff, along with others in the museums that make up a substantial portion of The Corporation, and interested parties outside the museums (often former directors), lobbied actively for the dismantling of The Corporation. (p. 560)

The restrictive relative clause occurs with one of two branches quasicoordinated to the head of the subject. The paraphrase removes that element from the sentential environment to allow it to be detailed without the need for a relative clause. This example also includes a restrictive verbless clause ("outside the museums"); these are dealt with next.

\section{Using Verbless Adjectival Clauses}

The restrictive information "outside the museums" in Example 12 could have been given in the form of the restrictive relative clause "who are outside the muse ums." However, as tense is not needed here and there is no need for a modal (can, should, might, etc.), we can "delete" the relative clause and the form of the verb "to be" -and so "convert" a relative clause to a verbless clause. The term "verbless clause" is used to describe all such passages of text, restrictive or non-restrictive, that are not otherwise classifiable as any of the other forms of noun phrase connection. Verbless clauses can be dominated by adjectives (often called adjectival clauses), by prepositional clauses, or by other means; appositions and many parenthetical insertions are verbless clauses.

Using the same argument for calling -ed and -ing clauses "clauses," we can stretch the definition further to include "clauses" that are not dominated by any form of the verb. Exactly how far the definition should be so used-or whether a new term should be coined-is open to debate. In this article I draw the line at verbless clauses and call stretches of text dominated by prepositions "preposition.l groups."

A restrictive adjectival clause appears at the end of the sentence in the following example:

"[T] he new programmes of assistance to museums fall under the direct responsibility of the Minister of Communication" to be administered by an Assistant-Deputy Minister upon the advice of an advisory committee. This committee would be "broadly representative of the museum community." 
(13) "[T] he new programmes of assistance to museums fall under the direct responsibility of the Minister of Communication" to be administered by an Assistant-Deputy Minister upon the advice of an advisory committec "broadly representative of the museum community." (p. 567, quotations in original)

The relative clause counterpart would be "which would be "broadly representative," but the shorter verbless clause dominated by the adjective "representative" is used instead.

In the next example a large adjectival clause is used to post modify a noun that is part of the subject of a sentence:

Over the years conflict in the priorities of an agency has become apparent. This agency is responsible for both the operations of the four national muscums and the granting programmes to other muscums in the country.

(14) Over the years conflict in the priorities of the agency responsible for both the operations of the four national museums and the granting programmes to other museums in the country has become apparent. (p. 565)

Again the use of the indefinite article becomes necessary in the paraphrase. The original uses an adjectival clause ("responsible . . in the country") to restrict the meaning of the noun "agency."

Adjectival clauses often occur with other types of restrictive clauses. Here is an example in which a restrictive relative clause is embedded within a restrictive adjectival clause:

Until the recent changes in the scheme for funding galleries ... many art museums experienced (and appreciated) little or no direction from the Canada Council. The Council hopes to enjoy a similar relationship with the federal government.

15) Until recent changes in the scheme for funding galleries ...many art museums experienced (and appreciated) little or no direction from 
the Canada Council, a relationship similar to that which the Council hopes to enjoy with the federal government. (p. 562)

The paraphrase emphasises the Canada Council as theme of a new sentence, whereas the original continues the relationship as theme of the restrictive adjectival clause dominated by the adjective "similar." Note that "which" is used for the restrictive relative clause to avoid the difficulty of two "thats."

\section{Using Prepositional Groups}

Prcpositional groups are by far the most common form of postmodification (see the index at the end of this paper). They are almost always used restrictively, and follow the pattern "preposition + definite article + noun." The term "preposition" is being used here in a wider sense than just for the indicators of position ("on, in, under,"etc.). We are also interested in the more metaphorical prepositions (such as "under' the control of," "'on top of 'the task," and "'on' (the subject of] the report") as well as the semantic prepositions such as "'for' (the purpose) of," "'by' the Council" [as agent], and "'of' Canada Council" [as possessive or related meanings].

Prepositional groups-arguably also "clauses"—often occur in strings of two, three or even more, in complex postmodified noun phrases. Some analyses of the semantics of such groups in the abstracts and titles of technical papers is available (Jordan, 1992), but there is otherwise little detailed analysis of this important aspect of English use.

An example containing prepositional groups at the end of the sentence is:

Following two ycars of planning and discussion the National Museum Policy was announced in 1972 and the National Museums of Canada was given the responsibility to administer the programmes of grants and services. These programmes were for museums throughout Canada.

(16) Following two years of planning and discussion the National Museum Policy was announced in 1972 and the National Museums of Canada was given the responsibility to administer the programmes of grants and services throughout Cáñada. (p. 557) 
The paraphrase required the classifying noun "programmes" after "these" because there are three plural nouns that "these" could refer to. The paraphrase must also contain a main verb, and so a decision regarding tense is necessary (is it "are" or "were"?). The need for an additional noun and a decision regarding tense is avoided in the original.

Example 16 shows coordination by and within the complex head of the total noun phrase ("The programmes ... Canada"). In the next example, coordination occurs in two parts of the noun phrase; it also demonstrates the use of prepositional groups based on deverbal nouns (Akimoto, 1989):

For example, The National Gallery of Canada has achieved considerable success in collecting and exhibiting art. This art is of the late 1960s and 1970s.

(17) For example, The National Gallery of Canada has achieved considerable success in the collection and exhibition of art of the late 1960s and 1970s. (p. 563)

The paraphrase uses a complex verb structure ("success in" + "-ing") to place "art" as the object of the first sentence; the original uses the deverbal nouns "collection" and "exhibition" with a prepositional group instead.

As discussed elsewhere (Jordan, 1993), deverbal nouns operate well with prepositional groups. Prepositional groups often occur with other restrictive postmodifiers. Here is an example including a prepositional group containing an -ed clause:

The Task force was shocked at a problem of low environmental quality. They were concerned about some buildings. These were occupied hy the national muscums.

(18) The task force was shocked at a problem of low environmental quality of some of the buildings occupied by the national museums. (p. 563)

It is extremely difficult to paraphrase writing containing several prepositional groups, as we see in the awkwardness of the paraphrase here. This points to 
the need for writers to be able to use strings of postmodifiers effectively. In the original here the restrictive -ed clause is embedded within the final prepositional group.

\section{Using to-Infinitive Clauses}

The to-infinitive clause as a pre-or post-clausal subordinator is a wellknown indicator of purpose, with its counterpart "means" information coming in the main clause (e.g., "To escape they jumped out of the window."). Purpose is also clearly indicated by the two to-infinitive clauses in:

(19) The purposes of the Corporation, as defined in the Act, are "to demonstrate the products of nature and the works of man ... so as to promote interest therein throughout Canada and to disseminate knowledge thereof." (p. 565)

The main purpose has two sub-purposes.

What is less well-known is that to-infinitive clauses are also used extensively within many complex verb structures and also (of interest to us here) as restrictive postmodifiers within complex noun phrases. Here is a simple example:

Even the basic requirements of care and cataloguing have more often than not gone wanting: all the National Museums suffer from a lack of staff. The duty of these staff is to care for the collections.

(20) Even the basic requirements of care and cataloguing have more ofien than mot gene wanting: all the National Museums suffer from a lack of staff wo care for the collections. (p. $56(6)$

The paraphrase uses a post-triggered associated nominal containing the clausesignalling word "duty" (meaning purpose); the original contains a to-infintive clause postmodifying the head noun "staff" to create the complex noun phrase ("a lack ... collections").

To-infinitive postmodifiers often occur in much more complex situations, as seen in: 
The Applebaum-Hebert report affirmed the idea of arm's length at a time when the federal government was embroiled in controversy. The controversy was over the introduction of formal ministerial directives. These directives were intended to ensure that crown corporations were in the public interest as determined by the elected government.

(21) The Applebaum-Hebert report aflimed the idea of arm's length at a time when the federal government was embroiled in a controversy over the introduction of formal ministerial directives to ensure that crown corporations were in the public interest as determined by the elected government. (p. 558)

The original contains a large to-infinitive clause postmodifying "directives," which is part of the two-stage prepositional group governed by the partitive preposition "of" and the situational preposition "over." This combination avoids the need for the re-entries of "controversy" and "directives" and the sentence starts with "The," "The," and "These," secn in the paraphrase.

To-infinitive clauses also occur as part of the subject of the sentence, as we will see in the next example. This example also contains an instance of a null-indicated relative clause combined with prepositional groups to end the sentence:

Renovations hover in the background for the Victoria building. These would be to improve the housing for the National Museum of Natural Science. The National Museum of Science and Technology looks on cnviously from an old bakery building. It has occupied that building from the beginning of its brief history.

(22) Renovations for the Victoria Building to improve the housing for the National Museum of Natural Science hover in the background and the National Museum of Science and Technology looks on enviously from the old bakery building it has occupied from the beginning of its brief history. (p. 568)

Four sentences become one in the original, which starts with a complex noun phrase ("Renovations... Science") containing a to-infinitive clause as well 
as two prepositional groups dominated by "for" (twice). The second part of the coordinated sentence includes a null-indicated relative clause to create a complex noun phrase to end the sentence. The relative pronoun "that" could have becn used to indicate the start of that clause.

\section{Using Other Clanse-Relational Indicators}

Purpose is just one of many "clause relations" (Winter, 1970), or "relational propositions" (Beekman and Callow, 1974), or "rhetorical predicates" (Longacre, 1974) that describe the semantic connections between clauses, sentences and paragraphs. They also apply as semantic connections between the head of a complex noun phrase and its restrictive postmodifier as we have just seen with the purpose relation. Here is a clear example of a time relation.

[M]odern art has been an elite practice. This has been true since the 1960 s.

(23) [M] Jodern art since the 1960 s has been an elite practice. (p. 562)

The original uses the clause "since the $1960 \mathrm{~s}$ " to post modify the noun "art," creating a complex noun phrase as the subject of the sentence.

The word "purpose" is one of a relatively few "Vocabulary 3 " words (Winter, 1977) that tell readers what the clause relation is. They provide more precise signalling of the relations than do coordinators (Vocabulary 1) and connectors (Vecabulary 2). Other Vocabulary 3 words are "cause, effect, result, basis, assessinent, method, ways, means, comparison, difference and similar." These words often occur with prepositional groups; two such instances occur in the following example:

The recommendations of the Massey Commission have been implemented in a piecemeal and uncoordinated way, and the Applebaum-Hebert Committee tried to identify the results of this. However the two groups gave different prominence to the idea of heritage, and this difference is significant. 
(24) The Applebaum Hebert Committee tried to identify the results of the piecemeal and uncoordinated implementation of the recommendations of the Massey Commission; a significant difference in their emphasis, however, was the prominence given to the idea of heritage. (p. 559)

The paraphrase has to establish the implementation before starting the main idea, whereas the original embeds this within a complex noun phrase. The original contains two Vocabulary 3 words and four prepositional groups. Note that it also contains a restrictive -ed clause dominated by the "given," as the verb "give" is irregular.

As the opposite relation to purpose is the means of achieving it, the two relations usually occur together. Here is an example containing a purposemeans relation as well as two prepositional groups as postmodifiers.

The Bovey Task Force made sixty recommendations, none of which to date has been acted upon. They deal with the broad environment of funding for the arts at a time when the government wants to reduce its contributions to arts and culture, and is seeking ways of doing this.

(25) The sixty recommendations of the Bovey Task Force (none of which to date has been acted upon) deal with the broad environment of funding for the arts at a time when the government is searching for ways to reduce its contribution to arts and culture. (p. 567)

The paraphrase still retains a two-stage prepositional group in the middle as there is no apparent way of avoiding that construction. The original uses a

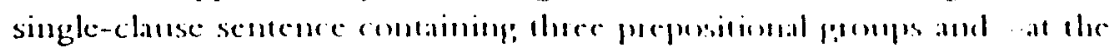
end-a means-purpose connection signalled liy the Vexabulary 7 word "ways" and the restractive on inimilive alousi:

\section{Using Coordinated Restrictives}

It is possible to have two or more branches of restrictive information about the head noun of a complex noun phrase. Here is an example of coordination within a prepositional group at the end of the sentence: 
The Canada Council, among other agencies, opposed the bill and rallied support. This support came from the arts community; it also came from the Conservative members of the Commons committee.

(26) The Canada Council, among other agencies, opposed the bill and rallied support from the arts community and Conservative members of the Commons committee. (p. 558)

The head noun of the complex noun phrase in the original is "support," and this is postmodified by the prepositional group ("from . . committee"). Coordination with "and" occurs within this group.

Coordination also occurs between two verbs within a restrictive relative clause in:

The Council developed funding programmes. These were for institutions, but were on the condition that they had to exhibit art work, and the work had to be by Canadian contemporary artists. The institutions also had to purchase such work.

(27) The council developed funding programmes for the institutions that exhibited and purchased art work by Canadjan contemporary artists. (p. 556)

The paraphrase avoids all complex noun phrases, but at considerable cost to readability. The elegance of the original is created by the two prepositional groups, the relative clause, and the coordination.

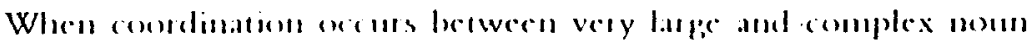

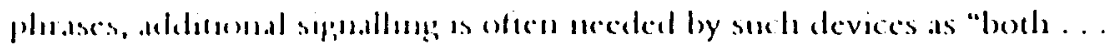
and" or "combined . . with." Here is such an example:

The Canada Council thereby awarded grants. These were for public art museums, and they enabled them to purchase works of art. The Council also initiated an acquisitions programme. This competed in the same market place with its public art museum clients in their principal function, collecting. The Council combined these two initiatives. 
(28) The Canada Council thereby combined the awarding of grants for public art museums to purchase works of art with a programme that competed in the same marketplace with its public art museum clients in their principal function, collecting. (p. 556)

The original contains two large, complex mom phases, the lis st commaininy, four prepositional groups and the second containing a relative clause and a prepositional group. It is only because of the compactness of these two complex noun phrases that they can be combined into a single sentence in this way.

\section{Using Split Nominals}

Large nominals-another term for noun phrases-can be split at any of their boundaries where a new clause or group starts. This is often done in the genre of abstracts, for cxample, to avoid an extremely large subject ending with a small verb phrase (e.g., "are studied") at the end of a sentence. Here is a simple example:

There are many misunderstandings, and these occur within and about NMC. They arise simply because of a lack of knowledge. This lack is about the activities of the Corporation, and it also concerns its various components.

(29) Many misunderstandings arise within and about NMC simply because of a lack of understanding of the overall activities of the Corporation and its various components. (p. 566)

The subject of the original sentence is the complex noun phrase, "Many misunderstandings within and about NMC," which contains a postmodified restrictive prepositional group dominated by the coordinated prepositions "within and about." This noun phrase is split at its boundary between the head noun ("misunderstandings") and the prepositional postmodification by the verb "arises." The original also contains two other prepositional groups, the second of which includes a coordination. 
The complex noun phrase is split by the verb and complement in the following example:

The forr mational muscoms of Canada could form administratively antomonoms, fiec-standing institutions and they could then be acountable for musetum performance. The prognosis is good for this.

(30) [T] he prognosis is good for the four national museums of Canada as administratively autonomous, frec-standing institutions accountable for museum performance. (p. 568)

The paraphrase does contain a postmodified noun phrase ("The prognosis of this"), but it is small and unavoidable. The complex noun phrase in the original is the whole of the sentence except for the verb ("is") and complement ("good"), which split the noun phrase after the head noun ("prognosis"). The original contains a prepositional group that including an adjectival clause dominated by "accountable."

There is a natural sequence for the order of strings of prepositional groups (as yet undocumented), and the "agentive" usually comes last. When, however, the noun phrase is long, or we wish to stress the agent, the agentive component can be used to split the natural sequence of prepositional groups. This can be seen in the following example:

All the past excuses for non-performance have been removed. This has heen achieved by the federal government, which has adopted recommendations. These have been advocated by the National Museums Tàsk Force.

(31) All the past excuses for non-performance have been removed by the adoption by the federal government of the recommendations of the National Task Force. (p. 568)

The first "by" in the original indicates means ("by means of") and the head noun of the final noun phrase is a deverbal noun ("adoption"). This head is postmodified by first the agentive component (dominated by "by") and then two nested prepositional groups. The agentive group splits the natural sequence of the noun phrase. 


\section{Converting Clauses into Anaphoric Noun Phrases}

Although many of the complex noun phrases studied so far include intra-sentential cohesive links, we have been more concerned with understanding the connections not just within the sentence but within the noun phrase itself. We will now turn our attention to noun phrases that have clear inter-sentential links. These are essentially of two types. The first are those that re-enter a noun or noun phrase to tell readers something more about it; these are "lexical" connections. The second type are those that re-enter a clause or sentence (or even a paragraph or more) into a "clause relation"; these are "semantic" connections. Most of the complex noun phrases that exhibit this features are "associated" in some way with something introduced earlier in the text.

\section{Using Untriggered and Triggered Associations}

When a noun phrase is lexically connected to an earlier noun or noun phrase it is said to be an "associated" noun plirase, or "associated nominal." When the new noun phrase does not mention the earlier one (the "trigger" [Hawkins, 1978]) in any way, it is said to be untriggered; and when the new noun phrase is restrictively postmodified by some mention of the trigger, it is called a "post-triggered associated nominal" (Jordan, 1984). Both types of association are included in the following example:

But the Task Force on the National Museums did not have far to look for discussions of the real problems of the National Museums of Canada ...

9) The National Museums of Canada have Internal Communication ...

This is weak. The National Muscums of C anduld have a stumente, and the problem is atributable to this.

(32) But the Task Force on the National Museums did not have far to look for discussions of the real problems of the National Museums of Canada... 
9) Internal Communication

Internal corporate communication is weak. The problem is attributable to the structure of the National Museums of Canada. (p. 566)

The trigger for section 9) is the "National Museums of Canada," introduced earlier in the text within the two postmodifying prepositional groups. The noun phrase "Internal Communication" is an untriggered associate, and the final noun phrase ("the structure ... Canada") is a post-triggered association because the trigger is used to restrictively postmodify the head noun ("structure").

Post-triggered associations can occur in two or more stages within the same complex noun phrase. This is shown in the following example:

The National Museums of Canada incorporate in a single administration Canada's four National Museums:

The National Museums of Canada have a National Programmes Branch, and this branch has five divisions. These divisions provide services and assistance to the Canadian museum community to further the objectives of this policy.

(33) The National Museums of Canada incorporate in a single administration Canada's four National Museums: The five divisions of the National Programmes Branch of the National Museums of Canada provide services and assistance to the Cantadian museum community (o) linther the objectivesolithis policy. (p. 5.5.3)

The paraphase fomally anounces the parts of the main topic. The complex noun phrase as subject of the original is a two-stage association using prepositional restrictive postmodification. The noun phrase at the end ("the objectives of this policy") is also a post-triggered association, re-entering the preceding sentence (not cited here) as, “policy" in the postmodification. 


\section{Using Other Post Triggers}

Although prepositional post triggering is by far the nost common method, all the other methods discussed here can be used. Lexical continuity in associations can also occur within the sentence. Both of these features can be secn in the next example, in which post triggering is achieved by an alchase:

The Gallery, at its appearance before the Task Force, dramatically underlined its burden of bureaucracy by wheeling in a shopping cart. This was full of reports, and these reports are required of The Gallery by The Corporation.

(34) The Gallery, at its appearance before the Task Force, dramatically underlined its burden of bureaucracy by wheeling in a shopping cart full of reports required of it by The Corporation.(p. 560)

The complex noun phrase in the original includes an adjectival clause dominated by "full," an -ed clause signalled by "required," and an agentive prepositional group indicated by "by."

Between sentences, post-triggered associations take the form "The $X$ of $Y$," where $X$ is a feature or part of the trigger and $Y$ is the trigger or some substitute for it. Within the sentence, the same form is used, except that the substitute form becomes "which." This is shown below:

The National Muscum of Man and the National Muscum of Natural Sciences were established and housed in the Victoria Building. This building has floors, and these slope dramatically.

(35) The National Muscum of Man and the National Museum of Natural Sciences were established and housed in the Victoria, the floors of which slope dramatically. (p. 555/6)

The paraphrase is absurd, of course, and an association is mandatory in such circumstances. Between sentences an acceptable form would have been "The floors of the building," but the original must be used within the sentence. 
The counterpart version for a pre-triggered version (where the trigger premodifies the head nom) would be "whose floors."

\section{Summary and Conclusions}

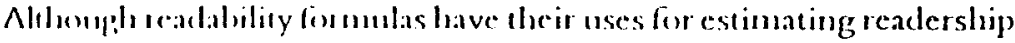
levels at the lenwe levels of teadership, the ir usefulness is limited at the higher lcvels of readership -a fact acknowledged by Gunning's catch-all " +13 " category. Indeed the principles of short sentence length and relatively few syllables on which many formulas are based are misleading criteria for judging the appropriateness of writing for linguistically sophisticated readers. In assessing such writing the very opposite approach is needed.

As a result of earlier corpus-based work that identifies complex noun plurases as being important stylistic markers of mature writing, we recognize the need for teachers of technical writing to more fully understand the complexities of the English noun phrase. And from pedagogical needs arising from weaknesses in student writing, we can recognize the need for established systems for paraphrasing single sentences and clauses into nominal form in different parts of the sentence. This article has sought to lay the groundwork for both these needs.

It is not that the principles espoused by readability formulas and much textbook advice on "clear" writing are wrong. It is more that they are limited to a relatively simplistic style of writing. While our students unquestionably need to be able to write relatively simple prose for some audiences, they also need to be able to write more complex prose for their fellow professionals and similarly educated readers. The students' understanding of the importance of "audience" for their work must go beyond the usual platitude that forms the psychological basis for all writing work; it must al so encompass a specific understanding of the effects of audience on word choice, sentence length, and clause and sentence structure. Such a genre-sensitive approach must include a knowledge of, and an ability to use, complex noun phrases.

We have seen that writing for mature audiences contains, as essential components, long complex noun phrases postmodified by various types of clauses and groups of text. The use of -ed, -ing, and relative clauses has been demonstrated in various positions in the sentence: at the end, at the start, and embedded within other structures in the middle. The connection between relative clauses and the other postmodifying forms is established, and both verbless clauses and prepositional groups are illustrated. Logical connection 
through Vocabulary 3 linking within the postmodification is explained, and some of the complexities of combinations of postmodifications are also discussed.

Untriggered and post-triggered anaphoric postmodified noun phrases are also explained as lexical associations linked to earlier nouns within the sentence and within the wider discourse. They are also identified as creating clause-relational cohesion connected to clauses and sentences earlier in the text.

To provide a means of further study based on the examples cited here, the following list of restrictive and non-restrictive postmodifications in the examples cited is provided. For each occurrence the example number and identifying information are given.

\section{Restrictive Postmodifiers}

-ed clauses: $1 /$ currently used, $4 /$ entrusted, 5/led, 6/decried, avoided, $10 /$ based, 11/published, 19/occupied, 21/as determined, 24/given, 34/re quired of it

-ing clauses: 7/reflecting, 8/representing, 9/contributing

relative clauses: $1 /$ that, $2 /$ through whom, $7 /$ when, 10/that, 11/that, 12/that, 15/which, 21/when, 22/it has occupied, 25/when, 27/that, 28/that

verbless clauses: 12/outside, 13/representative, 14/responsible, 15/similar, 30/accountable, 33/full

to-infinitive clauses (active): 1/to produce, 20/to care, 21/to cnsure, 22/to improve, 25/to reduce, $28 / 10$ purchase

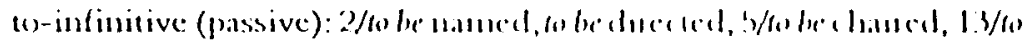
be administered

prepositional groups: 1/ofa new class of, 2/of the National Museum, in the federal structure, of a National Historical Museum, with access to, the creation of, 4/of our national collections of art, 5/a review of, of the Ontario, $6 /$ an example of the ... weakness of, $8 / 0$ f the ills of, the function of, 10/a position of, 11/under, the Report of, 12/the dismantlingof, 13/of assistance to, responsibility of, upon the advice of, 14/in the priorities of, the operations of, to other 
museums in, 15/in the schemefor, 16/of grants and servicesthroughout Canada, $17 /$ of art of, 18/of low environmental quality of, 19/The purposes of, the products of, the works of, 20\% of care, a lack of, 21/idea of, over the introduction of, 22/ Renovations for, for the National Museum of Natural Science, 24/results of, implementation of the recommendations of, 25/recommendations of, of funding for, contribution te, 27/for the institutions, by, 28/of grants for, clients in, with, 29/within and about, lack of understanding of the overall activities of, 30/ for the four national muscums of Canada, 31/excusesfor, the adoption... of the recommendations of, by, 32/the structure of the National Museums of Canada, 33/The five divisions of the National Programmes Branch of the National Museums of Canada, the objectives of, $34 / b y$

coordination: 2/Both...and, 8/and, 12/and, 14/both...and, 17/and, 19/and the works, 20/and, 26/and, 27/and, 29/and

clause relational: 23/since, 24/results, difference, 25/ways

split nominals: 29/arise, 30/is good, 31/by the federal government associations (post-triggered): 9/The judgment of its staff, $33 /$ The five divisions of the National Programmes Branch of the National Museums of Canada, 35/ the floors of which association (untriggered): $32 / 1$ uternal Communication, Internal corporate communication, The problem

\section{Non-Restrictive Clauses}

-ed clauses: 3/biased, 10/chaired

relative clause: 25/none of which

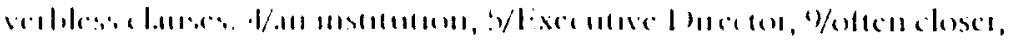
12/olien, 15/arclatimship

prepositional group: $26 / a m o n g$

Clearly further work is needed in identifying the complexities of postmodifications in English, and genre-analyses are badly needed to determine the extent of their use in different forms of writing and speech. But even at this stage this analysis points to the need to include elements of this 
work in writing curricula. This is especially so for more advanced courses, for which many teachers are complaining they have little to teach.

\section{References}

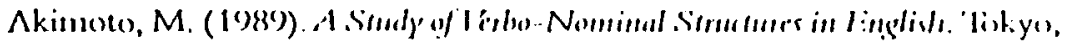
Japan: Shinozaki Shonin Press.

Beekman, J., \& Callow, J. (1974). Traisslating the Word of God. Grand Rapids MI: Zondervan.

Bell, Michael (1987). Museums and Federal Cultural Policy. Queen's Quarterly 94(3), 552-570.

Bruce, B., Rubin, A. \& Starr, K. (1981). Why Readability Formulas Fail. IEEE Transactions on Professional Communication, 24(1), 50-52.

Crystal, D., \& Davy, D. (1959). Investigating English Style. London: Longman.

Dale, E., \& Chall, J.S. (1948). A Formula for Predicting Readability. Educational Research Bulletin, 27, 11.

Drury, A. (1985). Evaluating Readability. IEEE Transactions on Professional Commmunication, 28(4), 1-14.

Flesch, R. (1951). How to Test Readability. New York: Harper and Bros.

Giles, T.D. (1990). The Readability Controversy: A Technical Writing Review. Jonrmal of Technical Writing and Commmnication, 20 (2), 131 138.

Gunning, R. (1968). The Techniques of Clear Writing. New York: McGraw Hill.

Hawkins, J A. (1978). Definiteness and Indefiniteness. London: Croom-Helm.

Karlinsky, S.S., \& Koch, B.S. (1983). Readability Is in the Mind of the Reader. The Journal of Business Communication, 20(4), 57-70.

Jespersen, O. (1940). A Modern English Grammar on Historical Principles. London and Copenhagen: George Allan Press. 
Johanmneson, N.L. (1982). On the Use of Postmodification in English Noun Phrases In W. Gutwinski, \& G. Jolly (Eds), The Eighth LACUS Formm, Iingruistirs Association of Canada and the United Stales (pp. 187195). (columbia, N(: I loublucam licss.

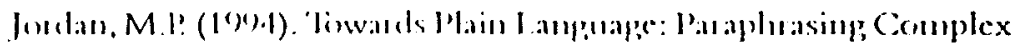

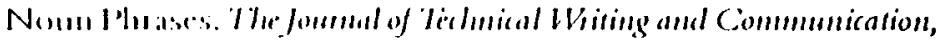
24(1), 77-96.

Jordan, M.P. (1993). Openings in Very Formal Technical Texts. Technostyle, $11(1), 1-28$.

Jordan, M.P. (1992). Beyond Impressionism: Evaluating Causal Connections In B. Fearing, \& K. Sparrow (Eds.) Advanced Technical Writing: Theory and Practice (102-114). New York: MLA.

Jordan, M.P. (1986b). Using Non-Finite Clauses in Editing. The Technical Writing Teacher, 13(3), 296-301.

Jordan, M.P. (1986a). The Genre of Technical Description. The Technical Writing Teacher, 13(1), 42-51.

Jordan, M.P. (1984). Fundamentals of Technical Description. Malabar, FL: Krieger.

Longacre. R.E. (1972). Hierarchy and Universality of Discourse Constituents in New Guinea Langunges. Washington DC: Georgetown University Press.

McClure, G.M. (1987). Readability Formulas - Useful or Uscless? IEEE Transactions on Professional Communication, 33(1), 12-15.

Plung, D.L. (1981). Readability Formulas and Technical Communication. IEEE Transactions on Professional Communication, 24(1), 52-54.

Poutsma, H. (1926-29). A Grammar of Late Modern English. Groningen: Noordhoff.

Powel, K.B. (1981). Readability Formulas are useful if . . . IEEE Transactions on Professional Communication, 24(1), 43-52.

Quirk, R., Greenbaum, S., Leech G., \& Svartvik, J. (1985).A Comprehensive Grammar of the English Language. London: Longman. 
Redish, J.C. (1981). Understanding the Limitations of Readability Formulas. IEEE Transactions on Professional Communication, 24(1), 4648.

Schenck, E.M. (1977). Technical Writer-Readability Formulas and the Non-Technical Reader. The Journal of Technical Writing and Communication, 7, 303-307.

Scheurwegs, G. (1959). Present-Day English Syntax. London: Longman.

Strong, W. (1973). Sentence Combining: A Composing Book. New York: Random House.

Sweet. H. (1891). A New English Grammar. Oxford: Oxford University Press.

Vervalin, C.H. (1980). Checked Your Fog Index Lately? IEEE Transactions on Professional Communication, 24(1), 87-88.

Wilkinson, A.M. (1992). Jargon and the Passive Voice. The Journal of Techuical Writing and Communication, 22(3), 319-325.

Winter, E.O.O. (1977). A Clause-Relational Approach to English Texts: A Study of Some Predictive Lexical Items in Written Discourse. Instructional Science, 6, (special issue).

Winter, E.O O. (1976). Replacement as a Function of Repetition, $\mathrm{PhD}$ Thesis, University of London, England. Dissertations Abstracts International, sec. C, Autumn, 38(4), 1-93. 